\title{
Assessing the Relational Nature of Child Physical Abuse and Neglect Among 12-Year-Old Girls
}

\author{
Corrine Ann Dale \\ Enculture Institute of Research and Program Development, St. Louis, Missouri
}

\begin{abstract}
Child maltreatment is a historical and current problem in the United States. Children are exposed to physical abuse, neglect, and sexual abuse in alarming numbers. In 2014, state agencies found an estimated 702,000 victims of child maltreatment. With two thirds of this group representing child neglect victims, research studies and effective interventions are needed for this group in particular. This study examined the relational nature of child neglect versus child physical abuse. The sample population consisted of 68 girls aged 12 years old at the Midwest site of the Longitudinal Studies of Child Abuse and Neglect research project. The secondary analysis was completed with descriptive, correlational, and multiple regression analyses. The results of the analysis revealed the mother-child relationship was significantly related to the presence of neglect and was significantly related to the presence of physical abuse. Peer relationships were not found to be significantly related to the presence of neglect or physical abuse. In the multiple-regression analysis, child neglect versus child physical abuse was more predictive of a negative mother-child relationship. Of note, the outcomes of the study lead to a better understanding of the need for relational interventions in treating victims of child abuse and neglect, as well as the relational nature of abuse and neglect demand interventions that focus on the victim and the caregiver/perpetrator. Such interventions can only result in socially and emotionally connected individuals, improving the functioning of the adolescent and the future adult.
\end{abstract}

Keywords: child neglect, child physical abuse, relational theory, girls

\section{Introduction}

Maltreatment of children is a social issue that continues to be a growing concern for social service professionals in the United States. In 2004, child neglect represented $60 \%$ of the child maltreatment reports (Bundy-Fazioli \& Delong Hamilton, 2013). In 2010, the rate of child neglect reports had risen to $78 \%$ in the United States, with physical abuse (18\% of reports) running a distant second (BundyFazioli \& Delong Hamilton, 2013; U.S. Department of Health \& Human Services, Administration for Children and Families, Administration on Children, Youth and Families, Children's Bureau, 2012). By 2016, 75\% of reported victims were neglected, $17.0 \%$ were physically abused, and $8.3 \%$ were sexually abused (U.S. Department of Health \& Human Services, Administration for Children and Families, Administration on Children, Youth and Families, Children's Bureau, 2018). While the rate of reported child neglect has remained high over the last 20 years, research focusing on this type of maltreatment has lagged behind that examining physical and sexual abuse. One reason for this deficiency may be that physical abuse is seen as more readily evident and treatable versus child neglect (Daniel, 2015). Not only does the research focused on neglect remain sparse, but consensus on treatment of children remains inconsistent (Chen, Propp, \& deLara, 2011; Jonson-Reida et al., 2019; Vandermindena et al., 2019). A review of the literature revealed a lack of studies that focused on child neglect and child physical abuse only, particularly with children transitioning from childhood to teen years. Therefore, the present study bridges the gap in studies involving older 
victims of child neglect and child physical abuse. Indeed, neglect and physical abuse affect children as they grow in different ways. To add to the knowledge base, the ability of child neglect versus child physical abuse to predict the level of mother-child and peer relationships among older children was explored.

A review of the literature confirmed that the majority of child neglect studies have used younger child populations (aged 0 to 3), the outcome of which have resulted in some interventions that may be effective with neglect that occurs at a younger age (Jackson, Cushing, Gabrielli, Fleming, O'Connor, \& Huffhines, 2016; Perry, 2001). These included home visits and parent-focused interaction under the guidance of professionals (Guterman \& Taylor, 2014; Pecora et al., 2014). Most of the interventions include the parent or caregiver and revolve around bonding exercises (Pecora et al., 2014). However, child neglect and physical abuse that occurs at an older age have been seen to negatively impact adolescent developmental trajectories (Toth, Gravener-Davis, Guild, \& Cicchetti, 2013). For example, child neglect and child physical abuse at an older age can affect levels of selfesteem and the development of social skills (Toth et al., 2013). The current study offered an opportunity to explore and examine factors that may interfere with healthy growth and development of relationships among young adolescents. Additionally, it is projected that the study results serve as a foundation for the development of interventions and treatment in older maltreated youth.

This is a quantitative, archival study that used data from the Longitudinal Studies of Child Abuse and Neglect (LONGSCAN) dataset, which consists of a consortium of five longitudinal research studies about child abuse and neglect. The research questions in this study focused on the relationship between child neglect and mother-child and peer relationships and between child physical abuse and mother-child relationship and peer relationships. The sample population consisted of 68 participants from the Midwest study site who were 12 years old and female. The child's perception of child neglect, child physical abuse, mother-child relationship, and peer relationship was examined. The four chosen LONGSCAN surveys were considered valid measures of the significance of child physical abuse and child neglect and mother-child and peer relationships in adolescent girls. To maintain relevance, the surveys examined these variables in the last year (except in the case of child physical abuse, where some items asked if this has ever occurred). Correlation and multiple regression analysis assessed the relationship between child neglect versus child physical abuse and peer and mother-child relationships. Specifically, child neglect and child physical abuse were hypothesized to affect these relationships and to therefore require a relational approach to treatment.

\section{Theoretical Foundation of Analyses}

Relational theory posits that true connections promote mutuality, empathy, and empowerment (Covington, 2007). In particular, the core concepts of relational theory include that (a) people grow through and toward relationships throughout the life span, (b) mature functioning involves movement toward mutuality and not movement toward separation, (c) building and maintaining relationships characterize growth, (d) growth-fostering relationships include mutual empathy and empowerment, (e) authenticity is necessary for relational growth and development, (f) growthfostering relationships is not a one-way street but offers all people the opportunity to benefit, and (g) the goal of relational growth and development is the increased capacity to connect over the life span (Jordan, 2010). The lack of a relational foundation results in disconnection, nonempathic, and toxic relationships resulting in psychological consequences (Covington, 2007). Psychological and relational disconnection is often seen in those suffering from physical or sexual abuse or other forms of trauma (Evans \& Burton, 2013). Consequently, the relationship between the abuser and abused is guided by nonempathic responses of the abuser, which leads to mental health symptoms such as dissociation, hypervigilance, and hyperarousal among the abused (Jordan, 2001). Jordan (2010) also surmised the 
traumatized individual lives in unsafe, non-growth-fostering relationships. In the current study, child neglect and child physical abuse are hypothesized to be traumatizing events that adversely impacts mother-child and peer relationships among older youth.

Because trauma such as child physical abuse and child neglect occur within the relationship, relational theory should guide the examination of the impact of these forms of maltreatment on the development of vital relationships beginning with the mother-child dyad. The toxic relationships that may result from maltreatment involving the mother-child relationship has been well documented (Jordan, 2001, 2010); however, identifying the differential impact of child abuse versus child neglect has not received as much attention as is warranted by the high level of substantiated child neglect and child physical abuse cases (Bundy-Fazioli \& Delong Hamilton, 2013). Researchers have found that relational traumas - traumatic events that occur in the context of an ongoing relationship and that involve the betrayal of important bonds-impact social, emotional, and psychological functioning as well as the mutuality required for healthy relationships (Birrell \& Freyd, 2006; Kaehler, Babcock, DePrince, \& Freyd, 2013). This study was guided by the construct of relational trauma as framed by relational theory and was based on the hypothesis that both physical abuse and child neglect would negatively impact mother-child and peer relationships as evidenced by deficit scores on mother-child and peer outcome measures.

\section{Definition of Child Neglect}

Research, interventions, and treatment protocols are guided by definitions. Bundy-Fazioli and Delong Hamilton (2013) offered a working definition of child neglect, stating it is a "parent's or caretaker's inability to meet a child's basic needs, potentially placing the child at risk of serious harm" (p. 251). This definition is associated with the act of omission, which child neglect represents. These researchers also recognized that poverty along with the lack of an identified support system and family resources are risk factors associated with neglect (Bundy-Fazioli \& Delong Hamilton, 2013). Manion (2011) defined neglect as invasive, difficult to tackle, and commonly seen in the population of children and adolescents brought to the attention of child protection services. Manion also explained neglect is often presented as a multiple, persistent, and complex issue. Yet maintaining public focus on neglect unlike physical abuse has been difficult (Manion, 2011).

In terms of relational theory, neglect is the absence of the opportunity to engage in growth-fostering activities that build and maintain relationships, resulting in chronic disconnection and isolation (Jordan, 2001). In cases of neglect, the lack of an available model can have long-term effects on both peer and caregiver relationships (Evans \& Burton, 2012). Future relationships may be derailed by the lack of knowledge on how to interact and engage in mutual exchanges, which are important factors in developing healthy relationships (Evans \& Burton, 2012; Jordan, 2001).

\section{Definition of Child Physical Abuse}

A definition of child physical abuse that is comparable to other definitions states that it is "nonaccidental trauma or physical injury caused by punching, beating, kicking, biting, burning or otherwise harming a child", and that "physical abuse is the most visible form of child maltreatment" (American Humane Association, 2003, para 1). Physical abuse has been associated with avoidant attachment style and results in dysfunctional relationships into adulthood (Unger \& De Luca, 2014). As an act of commission, physical abuse has led to emotional dysregulation, aggression, and coercive behavior, which results in relational disconnection and isolation (Azar, 2005).

In regard to relational theory, the coercive acts involved in child physical abuse demonstrates aggressive approaches as necessary components of interpersonal interaction (Azar, 2005). This approach leads to nonempathetic exchanges that may result in isolation and disconnection (Jordan, 
2001). Peer group as well as mother-child relationships require mutuality and empathetic exchanges, which the physically abused adolescent may lack exposure to and is, therefore, unable to be authentic in the relationship (Jordan, 2001). Thus, the physically abused adolescent may present as nonempathetic, aggressive, and harsh (Azar, 2005; Jordan, 2001: Muller, Thornbak, \& Bedi, 2012).

\section{Mother-Child Relationships}

In a study of parent-child relationships and their effect on adolescence, Ramirez (2016) described the parent-child relationship as one that includes attachment, monitoring, communication, and involvement. The researcher assessed these components and their impact on violent behavior or aggression among adolescents. Her definition of parent-child relationships was based on Hirschi's social bond theory, in which lack of attachment, commitment, belief, and involvement leads to delinquent behavior (Ramirez, 2016). Ramirez's study examined the impact of attachment, belief, and parental relationships on the likelihood of adolescents committing delinquent acts. In effect, she theorized that as parental relationships improved, delinquent acts, such as violent aggression, would decrease (Ramirez, 2016). Although the hypothesis was not supported, the idea that parental relationships, composed of attachment and belief, are important factors in social and peer connection was supported, as well as key to developing an understanding of how parent-child relationships progress from connection to disconnection. In the instance of deviant peer associations, the researcher cited the lack of an attachment and belief in the parental relationship as allowing for disconnecting acts such as violent aggression to occur (Ramirez, 2016). The attachment and belief in the parental relationship impacts the development of deviant peer relationships, as acts that will disappoint and result in disconnection from parents, in whom the attachment and belief is present, are avoided.

Guided by stress process framework and attachment theory, Withers, McWey, and Lucier-Greer (2016) examined the quality of parent-child relationships on adolescence. The researchers hypothesized that parent-adolescent relationship quality could be characterized by four distinct dimensions: closeness, communication, autonomy, and conflict. Additionally, using latent profile analysis, they predicted parent-adolescent relationships exhibiting high closeness, healthy communication, developmentally appropriate autonomy, and low conflict would be associated with low levels of adolescent mental health symptoms 2 years later. This research demonstrated a clear construct for examining the quality of parent-child relationships. The Withers et al. (2016) study lends itself to the identification of the psychologically damaging components of the mother-child relationship that may be impacted by child abuse and neglect.

Consequently, when viewed through the theoretical lens of relational theory, the mother-child relationship consists of mutual empathy and empowerment leading to connection and authenticity. In the case of child physical abuse and neglect these factors guide the development of relational schemas that results in less quality mother-child and peer relationships. It is hypothesized in the current study that child abuse and neglect are relational and predictive of disconnecting and isolating relationships in adolescence. In particular, isolating mother-child relationships among abused and neglected adolescent girls is thought to result in pathology that requires relational interventions.

In the current study, the mother-child relationship, and the impact of physical abuse and child neglect on the dyad, was assessed using self-report measures, and analyses, which were hypothesized to lead to treatment recommendations for the relationally and psychologically disconnected youth, were included. Current research supports the idea that the mother-child relationship begins prenatally and is lifelong (Withers et al., 2016). In the instance of the present study, the mother-child relationship is defined as mutual growth producing opportunities that 
produce empathetic exchanges leading to authentic and empowering relational connections (Miller, 2008). According to relational theory, mutually empathetic exchanges result in connected and emotionally stable individuals (Miller, 2008). This mutuality is especially vital to the motheradolescent relationship where the adolescent is expected to become more independent and less connected to the parent versus the peer (Warmuth \& Cummings, 2015).

\section{Peer Relationships}

During adolescence, peer relationships are expected to become significantly more important, to the detriment of the mother-child relationship (Warmuth \& Cummings, 2015). However, this proposed conflict may not necessarily have to be a consequence of growing older. A secure mother-child attachment relationship can provide the base for positive peer relationships (Warmuth \& Cummings, 2015). The peer relationship is expected to be positive when it involves mutuality and empathetic exchanges akin to a healthy mother-child relationship. While child physical abuse and neglect may result in socially and psychologically disconnected youth who are more susceptible to delinquency, low self-esteem, and social withdrawal, peers are chosen and maintained based on previous relational schemas that begins with the mother-child relationship.

Kim and Cicchetti (2010) claimed that maltreated children-particularly those who experienced the subtypes of neglect, physical and/or sexual abuse, multiple subtypes, and earlier onset-are more likely to have difficulties regulating emotions and show greater externalizing problems compared to nonmaltreated children. Because of disruptive and aggressive behaviors, they are more likely to be rejected by peers. Further, being deprived of important socialization experiences that positive peer interactions afford, these children become more vulnerable to stress and show increasingly higher levels of externalizing symptomatology. The researchers used a prospective longitudinal design to evaluate the hypothesis that earlier maltreatment experiences (particularly more severe subtypes, multiple subtypes, and earlier onset) are related to deficits in emotion regulation (Time 1), which are in turn associated with later maladjustment (Time 2) directly and/or indirectly through negative peer relations (Time 2), taking into account initial levels of maladjustment (Kim \& Cicchetti, 2010). The authors found child physical abuse and neglect resulted in emotional dysregulation, thereby negatively impacting peer relationships. In terms of relational theory, this research can lead to a discussion of how the lack of positive peer interactions leading to positive relational schemas, and the ability to connect through empathetic exchanges and mutuality, detrimentally impact the quality of both the mother-child and peer relationship.

In one of the few studies on the relational impact of maltreatment, aggression, and social withdrawal on peer relationships, Bolger and Patterson (2001) revealed the importance of both peers and relational maltreatment. Healthy peer relationships are defined as those that encourage empathy, connection, and prosocial viewpoints. This construct led the researchers to a conclusion that aggression is a byproduct of maltreatment and results in negative peer relationships (Bolger \& Patterson, 2001). Although social withdrawal was not found to result in poor peer relationships, this does not preclude the study of parental maltreatment and internalizing outcomes such as social withdrawal. It is especially relevant to the present study as the lack of relational opportunities is hypothesized to lead to social isolation and consequently poor models for positive peer relationships. In the current study, higher child physical abuse and neglect totals are expected to be predictive of the quality of mother-child and peer relationships. Child neglect versus physical abuse examined within the relational lens is expected to further discussions on the impact of maltreatment on peer relationships and to lead to a better understanding of relational schemas and the processing of child abuse and neglect among female adolescents. 


\section{Child Abuse and Neglect and Girls}

Azar (2005) reviewed the impact of systemic issues in regard to abused and neglected girls within the framework of historical treatment of women and girls, especially among minority women, in contact with the child welfare system. The researcher maintained physical abuse and neglect occurs within relationships and it is these relationships that need to be targeted for intervention (Azar, 2005). This observation is important in developing treatment for girls who have encountered maltreatment, especially those who are from diverse backgrounds. Based on Azar's (2005) review, it can be surmised that mother-child relationships are reflected in a lack of mutuality and often involve a cycle of abuse and neglect that stems from social inequalities as well as relational deficits. In fact, Azar (2005) reiterated that not only have maltreated girls experienced a lack of care and abuse, they have a high likelihood of observing their most closely allied role model, their mothers, also not being treated with respect and at times abused by others (e.g., battering partner, difficult welfare office encounters, etc.). This internalization of global images related to a lack of worth, helplessness, and acceptance of one's role as victim may work against effective treatment (Azar, 2005). Indeed, careful attention to the other pressures encountered by girls and their families may also be crucial (e.g., economic strain, domestic violence, dating violence, etc.) to treatment development and intervention (Azar, 2005). Azar's research leads to the observation that relational schemas are vital to the discussion of the impact of child abuse and neglect on the quality of foundational relationships among girls.

With the goal of assessing girls' perceptions of their abusive and neglectful experiences, Sigad, Beker, Lev-Wiesel, and Eisikovits (2015) interviewed 20 adolescent girls who were identified by the Israeli child welfare system. Through these interviews, the researchers found common themes, which included dissociation, isolation, and withdrawal. They found female victims may cope with abusive experiences by detaching and distancing themselves from abusive events. This approach, while comforting and potentially effective in the short term, can lead to the type of isolation relational theorists maintain is at the heart of pathology for girls (Covington, 2007; Sigad et al., 2015). To assist with returning girls to the connection and to relational competence, it must be understood that processing the abuse and neglect requires an approach that includes safe relationships and assistance with nonlinear narrative revelations which are rather incremental, characterized by cyclical periods of engagement and disclosure that alternate with periods of denial or delay (Sigad et al., 2015). The Sigad et al. study lends itself to the idea that child abuse and neglect among adolescent girls is driven by the relational nature of the abuse and by the subsequent relational framework directing the coping of the individual as she processes being both victim and survivor.

\section{Adolescence and Relational Treatment}

Toth et al. (2013) explained that intervention during adolescence should involve the understanding of two factors. First, adolescence is a transitional turning point in development that presents opportunities and challenges for developmental milestones that include developing an identity and forming romantic relationships (Toth et al., 2013). Before relational theory, everyone was thought to go through the same stages of individuation (Covington, 2007). Instead, relational theory proposes that growth and development occur through relational connection and requires that treatment to combat the effects of abuse implement relational techniques through the therapeutic alliance (Covington, 2007; Jordan, 2010). However, in treatment of abuse and neglect, many still use seminal techniques, which mainly include cognitive behavior therapy and family system therapy (Carr, 2019). It is evident that these interventions ignore the driving force behind child abuse and neglect and ignores the literature, which supports the idea that child abuse and neglect is relational in nature and can have a greater impact on relationships as one grows older (Toth el al., 2013). In 
particular, the relational impact of child maltreatment on older youth requires more examination. Although Cashmore (2011) explained that infants and children are especially vulnerable to abuse and neglect, with the window for secure attachment impacted by poor parenting, this is not the only period of vulnerability; early adolescence is also a time of increased risk. Consequently, research should focus on the vital social and emotional bonds that guide mother-child and peer relationships during this period. Accordingly, further development of this idea forms the synthesis of this study.

\section{Method}

\section{Participants}

The LONGSCAN dataset was composed of interviews involving parents and children from birth to 18. The dataset is composed of five sites that range from children at risk of child maltreatment to those who were victims of child maltreatment. The attrition rate from baseline to age 14 was $25 \%$ (Runyan et al., 2014). Table 1 offers a visual of the LONGSCAN population. Except for the Seattle, Washington, site, the majority of the populations is of African American descent. Girls are the majority at each site. This preliminary examination is consistent with the contention that the population represents people of color who are female, which is also reflective of the child welfare population (U.S. Department of Health \& Human Services, Administration for Children and Families, Administration on Children, Youth and Families, Children's Bureau, 2018).

Table 1. A Brief Description of the Longitudinal Studies of Child Abuse and Neglect Samples

\begin{tabular}{|c|c|c|c|c|c|c|}
\hline Demographic & $\begin{array}{c}\text { Baltimore } \\
(n=282)\end{array}$ & $\begin{array}{l}\text { Chicago ( } n \\
=245)\end{array}$ & $\begin{array}{c}\text { North } \\
\text { Carolina } \\
(n=243) \\
\end{array}$ & $\begin{array}{c}\text { San } \\
\text { Diego }(n \\
=330) \\
\end{array}$ & $\begin{array}{c}\text { Seattle } \\
(n= \\
254) \\
\end{array}$ & $\begin{array}{l}\text { Total }(N \\
=1,354)\end{array}$ \\
\hline Cohort birth year & $1988-91$ & 1991-94 & $1986-87$ & 1989-91 & 1988-94 & 1986-94 \\
\hline \multicolumn{7}{|l|}{ Race (\%) } \\
\hline $\begin{array}{l}\text { African } \\
\text { American }\end{array}$ & 92.9 & 53.5 & 63.0 & 37.6 & 20.5 & 53.3 \\
\hline Caucasian & 5.0 & 13.1 & 35.8 & 28.5 & 50.0 & 26.2 \\
\hline Hispanic & 0.4 & 13.9 & 0.0 & 16.7 & 2.8 & 7.2 \\
\hline Mixed & 1.1 & 17.1 & 1.2 & 15.8 & 24.0 & 11.9 \\
\hline Other & 0.7 & 2.4 & 0.0 & 1.5 & 2.8 & 1.5 \\
\hline \multicolumn{7}{|l|}{ Gender (\%) } \\
\hline Male & 52.1 & 46.9 & 45.3 & 47.3 & 50.8 & 48.5 \\
\hline Female & 47.9 & 53.1 & 54.7 & 52.7 & 49.2 & 51.5 \\
\hline \multicolumn{7}{|l|}{$\begin{array}{l}\text { Maltreatment } \\
\text { status at } \\
\text { recruitment (\%) }\end{array}$} \\
\hline Reported & 24.1 & 60.8 & 34.2 & 100.0 & 100.0 & 65.3 \\
\hline At risk & 36.5 & - & 56.8 & - & - & 17.8 \\
\hline Control & 39.4 & 39.2 & 9.0 & - & - & 16.9 \\
\hline
\end{tabular}

The current study included 68 girls, age 12, who were assessed at the Midwest site and who completed the four study surveys reflecting quality of mother-child and peer relationships and the level of child physical abuse and child neglect. The study's demographic data revealed that $78 \%$ of the sample population was of African American descent (see Table 2). 
Table 2. Demographics of the Sample Population: Race

\begin{tabular}{lccc}
\hline Race & Frequency & \% & Cumulative \% \\
\hline Caucasian & 4 & 5.9 & 4.9 \\
African American & 53 & 77.9 & 83.8 \\
Hispanic & 4 & 5.9 & 89.7 \\
Native American & 1 & 1.5 & 91.2 \\
Mixed & 6 & 8.8 & 100.00 \\
\hline
\end{tabular}

Also, the data revealed that for the majority of this study's population, the income level is between $\$ 5,000$ and $\$ 10,000$ per year (see Table 3). This is not outside the current makeup of the child maltreatment population, which is mainly people of color living in poverty with little or no resources (Bishaw, 2011; U.S. Department of Health \& Human Services, Administration for Children and Families, Administration on Children, Youth and Families, Children's Bureau, 2018).

Table 3. The Demographics of the Income of the Sample Population

\begin{tabular}{lccc}
\hline Annual Income & Frequency & \% & Cumulative \% \\
\hline$\leq \$ 5,000$ & 19 & 27.9 & 27.9 \\
$\$ 5,001-10,000$ & 24 & 35.3 & 63.2 \\
$\$ 10,001-15,000$ & 8 & 11.8 & 75.0 \\
$\$ 15,001-20,000$ & 11 & 16.2 & 91.2 \\
$\$ 20,001-30,000$ & 2 & 2.9 & 94.1 \\
$\$ 25,001-25,000$ & 1 & 1.5 & 96.6 \\
$\$ 30,001-35,000$ & 1 & 1.5 & 97.1 \\
$\$ 35,001-40,000$ & 0 & 0.0 & 97.1 \\
$\$ 40,001-45,000$ & 0 & 0.0 & 97.1 \\
$\$ 45,001-49,999$ & 0 & 0.0 & 97.1 \\
$\geq \$ 50,000$ & 2 & 2.9 & 100.0 \\
\hline
\end{tabular}

\section{Measures}

\section{Mother-Child Relationship}

The mother-child relationship was examined by the Quality of Mother Relationship survey, which is intended to assess an adolescent's perception of the quality of the relationship with his or her mother or mother figure and the level of their recent involvement, as well as the adolescent's perception of the mother's educational aspirations for the youth (Knight, Smith, \& Martin, 2010). The questions include the following: "Have you talked about your friends or things you were doing with friends with her?" "Have you talked with her about a personal problem you were having?" and "Have you talked with her about other things you're doing in school?" (Knight et al., 2010, p. 119). The measure is considered reliable with internal consistency for the Quality of Relationship scale, which reported mean scores for the LONGSCAN sample as excellent ( $\left.\alpha_{\text {age12 }}=.82 ; \alpha_{\text {age } 14}=.85\right)$, and with internal consistency for the Mother Involvement sum scores for the LONGSCAN sample as good ( $\alpha_{\text {age12 }}=.69$; $\left.\alpha_{\text {age14 }}=.68\right)$. Higher scores indicate higher levels of relationship quality, mother involvement, and mother's perceived educational aspirations for adolescent. The validity of the measure was reflected in the significant correlation between three quality relationship measures, which included the child report of mother, the child report of father, and the caregiver report of child and between measures at both ages 12 and 14 (Knight et al., 2010). 


\section{Child Neglect}

The evidence of child neglect was assessed by using the About My Parents survey. It is a self-report survey that assesses the adolescent's perception of child neglect. There are four subscales: Physical Needs, Emotional Support, Monitoring Supervision, and Educational Support (Knight et al., 2010). Higher scores indicate less neglectful/more optimal parent behavior (Knight et al., 2010). The survey was adapted from the Neglect Scale and included revisions assessing how often parents met some of their child's needs and included questions such as "How often did things with you just for fun" and "How often you were helped you with your homework" (Knight et al., 2010, p. 3). The LONGSCAN scale focus on parent behaviors during elementary school and in the last year, while the original Neglect Scale asks about life in general with specific parent figures identified by the adolescent. LONGSCAN revised the response set from strongly agree to strongly disagree, to a 4-point scale ranging from 0 (never) to 3 ( $a l o t$ ). The Neglect Scale showed good reliability and validity and the LONGSCAN revisions are expected to reflect the same psychometric support. For this study, the scales were used to assess the child's perception of neglect in the last year (Knight et al., 2010).

\section{Peer Relationship}

The Peer Relationship survey used a scale that includes seven adolescent self-report items on peer relationships. Three items assess the adolescent participant's perception of how "other kids" at school treat them, and single items ask "whether or not s/he has a best friend, a friendship group, and the level of satisfaction with these friendships" (Knight et al, 2010, p. 93). The measure is useful in assessing a group who has experienced peer relationship problems, with $53 \%$ answering that almost no one at school is friendly toward them and 70\% reporting that most kids ignored them. Moderate correlation between self-report of peer relationships and teacher estimation of peer status was found in the Teacher Estimation of Peer Status measure, and between the $t$ scores of Internalizing Behavior and Social Competence scales of the Child Behavior Checklist and the Youth Self-Report measures. Higher scores on individual items of the Teacher's Estimation as well as the Peer Relationship survey reflect more peer problems.

\section{Physical Abuse}

The Self-Report of Physical Abuse and Assault measure is designed to assess a young adolescent's self-reported lifetime history of physical abuse and assault. Physical abuse includes 15 items that include endangerment and physical injury items. Physical injury items include questions such as "Has any adult ever burned or scalded you on purpose?" "Has any adult ever cut or stabbed you with a knife, razor, fork or something sharp like that?" "Has any adult ever done something else that badly physically hurt you or put you in danger of being hurt?" "Has any adult ever bruised you, or given you a black eye?" (Knight et al., 2010, p. 157). Higher scores on these items indicate more physical abuse or assault experienced. Thus, scores were summed and lead to an overall score indicative of child physical abuse (Knight et al., 2010). At the present time, there are no validity or reliability studies published on this measure. After specifying gender, this study population was reduced to 68 girls aged 12 years old from the Chicago, Illinois/Midwest site.

\section{Data Collection}

LONGSCAN is a consortium of research studies operating under common bylaws and procedures. It was initiated in 1991 with grants from the National Center on Child Abuse and Neglect through a coordinating center at the University of North Carolina Injury Prevention Research Center and five satellite sites Chicago (Midwest); Baltimore, Maryland (Eastern); North Carolina state (South); San Diego, California (Southwest); and Seattle (Northwest; Knight et al., 2010). Each site is conducting a separate and unique research project on the etiology and impact of child maltreatment (Knight et al., 2010). While each project can stand alone on its own merits, through the use of common assessment 
measures, similar data collection methods and schedules, and pooled analyses, LONGSCAN is a collaborative effort.

In the present study, the Chicago (Midwest) sample was used, which included 245 participants, 53\% of whom were girls (Knight et al., 2010). The sample population consisted of 68 girls aged 12 years old who had completed self-reported About My Parents, Child Physical Abuse, Quality of MotherChild, and Peer Relationship surveys, which were chosen to accurately assess the research variables. The original data collection was designed to measure the onset and progression of children's social, emotional, and behavioral outcomes from preschool through young adulthood (Hunter \& Knight, 1998). In particular, in this study, the perception of child neglect, child physical abuse, and motherchild and peer relationships was examined using measures from the Midwest site of the LONGSCAN study.

\section{Results}

Girls interviewed at age 12 using child neglect, child physical abuse, and quality of mother-child and peer relationships measures to assess the adverse relational outcomes of child physical abuse and neglect, were chosen as part of this study. Correlational analyses were conducted to determine if a relationship existed between mother-child and peer relationships and the presence of child neglect and child physical abuse. The mother-child relationship was significantly related to the perception of neglect $(r=.475, n=68, p<.01)$. This was a positive relationship that revealed that as mother-child relationship totals increased, perception of less neglectful behavior increased. The mother-child relationship also revealed significance among physical abuse. The physical abuse analysis revealed that as the perception of the quality of the mother-child relationship increased, the self-report of physical abuse decreased $(r=-.411, n=68, p<.01)$.

The peer relationship did reveal a positive relationship, but not at a significant level. Correlation analysis of peer relationship demonstrated positive relationship with physical abuse $(r=.342)$ and neglect $(r=.623)$ that, while not significant, encourages future investigation into the impact of child physical abuse and neglect on the peer relationships of older youth. The mean score on the peer measure was 7.0 out of a maximum of 12.0 , with higher scores indicative of negative peer relationships, leading to a foundation for future investigation into the value of peer relationships among maltreated older youth. Because correlational analysis was not significant, peer relationships were not included in the multiple regression analysis. However, this does not eliminate peer relationships from the discussion as an important relationship among adolescent girls.

Based on the correlation analyses, a multiple regression model was conducted on the criterion variable mother-child relationship and the predictive variables child neglect and child physical abuse. Table 4 represents the model summary, $R^{2}=.203, F(2,65)=9.522, p<.01$. The equation revealed that $20 \%$ of the variance is accounted by neglect among the mother-child relationship. As the total for more optimal/less neglectful behavior increases, the perception of the quality of the mother-child relationship increases. As indicated in Table 4, the $b$ weight indicated that for every point increase in the mother-child relationship, there is a .252 increase in neglect. There was also a significant relationship between child physical abuse and the mother-child relationship. This was a negative relationship, which indicated that higher mother-child relationship scores lead to lower physical abuse scores. The $b$ weight indicated that for every point increase in the mother-child relationship, there is a -.376 change in physical abuse. Physical abuse, $R^{2}=.148, F(2,65)=6.814, p$ $<.005$, accounts for $15 \%$ of the variance between child physical abuse and the mother-child relationship. When compared to the $20 \%$ of the variance in the child neglect and mother-child relationship, the analyses led to the conclusion that physical abuse is not more predictive of a negative mother-child relationship. While physical abuse was predictive of the mother-child relationship, it did not exceed the predictability of child neglect and the mother-child relationship. 
Overall, multiple regression analysis resulted in a more predictive relationship between child neglect versus child physical abuse and the mother-child relationship.

Table 4. Multiple Regression Model

\begin{tabular}{lcccc}
\hline Variable & $\boldsymbol{M}(\boldsymbol{S D})$ & $\begin{array}{c}\text { Correlation } \\
\text { with mother } \\
\text { relationship }\end{array}$ & $\boldsymbol{b}$ & $\boldsymbol{B}$ \\
\hline Mother total & 7.00 & 1.00 & & \\
& $(5.634)$ & & & \\
Neglect total & 63.224 & $.475^{* *}$ & .252 & .382 \\
& $(7.763)$ & & & \\
Physical abuse total & 1.177 & $-.411^{* *}$ & -.838 & -.382 \\
& $(2.614)$ & & & \\
${ }^{* *} p<.01$. & & & &
\end{tabular}

\section{Discussion}

The findings revealed that the mother-child relationship is important in adolescence as well as infancy. In infancy, the relationship is referred to as the attachment relationship (Perry, 2001). It has been advanced that if a secure attachment relationship is not established then future relationships would be framed by this deficit (Perry, 2001). This absence of secure attachment can be seen in relational deficits evident in older youth who are victims of child abuse and neglect (Perry, 2001). In the case of physical abuse, the correlation was, in fact, a negative one in which child physical abuse and the mother-child relationship had an inverse relationship. In other words, as the number of physically abusive behaviors increased, a decrease in the level of perception of positive mother-child relationships resulted. In the case of child neglect, the relationship was positive, which indicated the higher the level of nonneglectful behavior, the greater the perception of positive mother-child relationships. The results of the correlation led to a multiple regression model in which child neglect versus child physical abuse was found to be more predictive of the mother-child relationship. While this connection between both child physical abuse and child neglect and the mother-child relationship may be seen in the bonding and attachment relationship that may have occurred in infancy, it is reinforced here that there continues to be a need for a relational connection to a caregiver even at age 12 (Warmuth \& Cummings, 2015).

\section{Child Physical Abuse and Neglect and the Mother-Child and Peer Relationship}

The relationship between physical abuse and the mother-child relationship versus the peer relationship maybe a reflection of attachment and bonding that occurs in infancy. This may explain why the mother-child relationship indicated a significant relationship although the peer relationship did not. Perry (2001) explained the attachment relationship that occurs in infancy requires a bond to a particular caregiver. The results of this study appear to concur with the literature in that the attachment relationship is the foundation of relationships and has a long-term effect on the motherchild relationship. Conversely, this bonding differentiates the caregiver relationship from the peer relationship in adolescence. It would be expected that physical abuse and neglect impact both mother-child and peer relationships. However, the results demonstrated an impact on the motherchild relationship without the concurrent impact on the peer relationship. Although physical abuse and neglect occur within the caregiver relationship, this does not translate into a relational factor that impacts both mother-child and peer relationships. In fact, the results of the analysis, which revealed the impact of child neglect and child physical abuse on peer relationships were not significant, challenge the literature, which has peer group and peer relationships as among the most 
important factors in recovery for maltreated adolescents (Benedini, Fagan, \& Gibson, 2016; Kim \& Cicchetti , 2010; Laursen \& Collins, 2009; Yoon, Yoon, Park, \& Yoon, 2018).

As stated, child neglect revealed a significant relationship between the mother-child relationship without the concurrent impact on the peer relationship. Among older victims, child neglect is the absence of relational growth producing opportunities and the absence of extending bonding experiences into later years (Perry, 2001). In an adolescent, it may represent itself as a failure to connect with same aged peers. As the bonding and attachment relationship occurs in infancy, the occurrence of neglect in adolescence can also lead to insecure attachment and a lack of bonding experiences (Perry, 2001). In fact, this may lead to relational deficits throughout the life span (Toth et al., 2013). Overall, the findings suggest child neglect has a relational impact that can lead to psychologically damaging disconnection and isolation in older maltreated youth.

\section{Understanding the Relational Nature of Child Physical Abuse and Child Neglect}

Childhood physical abuse is linked to poor intimidate relationships in adulthood (McLeod, Fergusson, \& Harwood, 2014; Muller et al., 2012). It was expected that child physical abuse would be related to poor mother-child and poor peer relationship because the research appears to support this hypothesis (McLeod et al., 2014). Accordingly, the relationship in this study is seen to have an inverse affect, in which as physical abuse increases the level of the mother-child relationship decreases. However, the peer relationship was not significant in this study. This may be a result of the social-desirability bias in the self-report questionnaires, or it may reflect the fact that child physical abuse does not impact peer relationships as adversely as first hypothesized. This may also be a result of the reduced level of child physical abuse reported in this study. The lack of reported physical abuse in this population may have resulted in a concurrent lack of connection between physical abuse and peer relationships. Subsequently, this leads to more focus on the child neglect hypotheses as stated initially.

The presence of a positive correlation between child neglect and mother-child relationship led to an analysis of the mother-child relationship versus peer relationships. While both correlations were significant, the mother-child relationship and neglect resulted in significance, which led to a 99\% certainty that the relationship was not due to chance alone. This interpretation led to a further understanding of child neglect and the mother-child relationship. Because child neglect is the absence of factors that help to form the relationship, it can be postulated that an absence of these factors also impacts ones' ability to establish and maintain peer relationships.

Consequently, the analysis of child neglect resulted in the conclusion that it provides a foundation upon which future examination of mother-child relationships can be built. It is consistent with the supposition that the absence of factors associated with the relationship leads to a lack of a foundation for healthy relationships. With the understanding that child neglect and its impact on the mother-child relationship pave the way for the relational nature of child abuse and neglect, the need for more studies in this area is supported.

The analyses involving 12-year-old girls were indicative of the proposed health of future relationships among this group. The lack of a correlational relationship indicated that peer relationships among this age group may not be as vital as first thought. The perception of child neglect emerged as the most important factor in building and maintaining relationships. It may be maintained that the absence of connecting factors, as seen in child neglect, is more important than the presence of aggressive connectors, as seen in physical abuse.

The concepts of relational theory are present in the child neglect and physical abuse and motherchild relationship analysis. These concepts, which range from mutual growth producing 
opportunities to building and maintaining relationships characterizing growth, were the foundation of the relational nature of child neglect (Covington, 2007; Jordan, 2010). Because the analysis revealed a positive correlation between child neglect and the mother-child relationship and a negative relationship among child physical and mother-child relationships, interventions can be designed with the adolescent population in mind. Understanding that relational interventions are the optimal approach to the treatment of child neglect was a focus of this research study. From secure attachment to bonding to mutually empathetic relationships, the study found child neglect has an impact on the relationships of the future adult. This, in turn, calls for future relational-based research among adolescents who are victims of child neglect alone.

\section{Implementing Relational Treatment}

The study results revealed child neglect is more predictive of the mother-child relationship than of child physical abuse among 12-year-old girls. Based upon this result, a look at the relational nature of child neglect can help to lead to an effective form of treatment. Perry (2001) listed keys to resiliency and stated the development of a more positive mother-child relationship in the face of child neglect and child physical abuse can occur with anyone who is consistently available, who interacts in a positive manner, and who is emotionally connected. While child neglect is the omission of these entities, as a 12-year-old, neglect may largely impact the mother-child relationship but not the peer relationship. Yet, the social and emotional ramifications of maltreatment at 12-years-of age lead to a need for individual as well as mother-child psychological treatment. Indeed, it appears the 12-year-old can understand the reasons for the disconnection she may feel, as well as understand the need to trust and feel safe to grow within mutually empathetic relationships.

The understanding of this disconnection and need to trust and feel safe lead to a desire for a form of therapy that is relational and that presents an empowering and safe therapeutic alliance. The mother may not be able to immediately provide this, as child neglect or child physical abuse may be committed by her, and the trust, safety, and connection will take time to reoccur. However, relational therapy allows the victims to grow through the therapeutic relationship. The core relational principles ranging from empathetic exchanges to empowerment are instituted during therapy. Following the establishment of what a healthy relationship entails, the mother can join the sessions, with the goal of hearing and understanding the child's story. The therapist and caregiver should understand that adolescents must feel safe and connected enough to tell their story and describe their journey, following the neglect or abuse. This view can lead to a path of reconnection and a rebuilding of the relational foundation that offsets the feelings of low self-worth and the turning away from relationships that may occur in neglected and abused adolescents (Covington, 2007).

\section{Limitations of the Study}

The LONGSCAN data is a longitudinal dataset that allows analyses of secondary data. In this research study, the relational nature of child neglect and child physical abuse was examined. The focus was on 12-year-old girls and their perception of child neglect or child physical abuse. Therefore, the results of the study were limited by age, gender, location, and income. Once the data were cleaned and missing data transformed, the results were limited to 12-year-old girls who were of African American descent, reflecting the assertion that child maltreatment risk factors include being poor, being female, being younger, and being African American (World Health Organization, 2016).

Although there were significant negative data related to child physical abuse, there was a low level of reported child physical abuse. Girls averaged 1.1 on a scale of 10 in the report of child physical abuse. The regression data revealed a decrease in predictive ability of child physical abuse versus child neglect that may be a result of the self-report survey, which revealed little to no physical abuse in the sample. The lack of reported physical abuse may also be due to the extreme nature of the 
questions asked. Thus, the results may be limited to child neglect and the ramifications of this form of child maltreatment. Although the location of the study was limited to the Midwest site, it may be possible to generalize the results to other locations, as each site involved administered the same selfreported questionnaires. It should be noted that the age limitation applies across all sites.

\section{Conclusion}

Child neglect and child physical abuse are among the most prominent forms of child maltreatment. Although child neglect makes up $75 \%$ of child maltreatment reports, it is not studied as often as child physical abuse and child sexual abuse (Bundy-Fazioli \& Delong Hamilton, 2013; U.S.

Department of Health \& Human Services, Administration for Children and Families, Administration on Children, Youth and Families, Children's Bureau, 2018). Up to this point, research on child physical abuse was considered more significant because of the easily identified components of physical abuse (Daniel, 2015). This study was vital in starting the conversation on the impact of child neglect on relational growth and development. The study analysis revealed that child neglect is more predictive of relational deficits, specifically in the mother-child relationship. While peer relationships are prominent in adolescence (Benedini et al., 2016; Ryan, Williams, \& Courtney, 2013; Tucker, Edelen, Ellickson, \& Klein, 2011; Yoon et al., 2018), this study did not show the importance of peer relationships among 12-year-old female victims of abuse and neglect.

Only the mother-child relationship was found to be significant among the study's sample exposed to child neglect. This result can be used to establish treatment and prevention programs and to also begin the conversation around child neglect, which is rarely studied in older youth. The study lends itself to a list of understanding that includes the following factors: (a) child neglect may not have an impact on peer relationships, (b) child neglect is more predictive of foundational relationships than physical abuse, and (c) treatment for child neglect is dependent on the understanding of the absence of relationship building opportunities.

Several changes may result from this better understanding of child neglect and child physical abuse and relationships among older youth. First, relational theory should frame intervention of child abuse and neglect. Second, assistance with telling the abuse story in a nonlinear manner can ensure the connection or reconnection of individual to family and society. Third, the fact that relationships

appear to be more impacted by the absence of a healthy relational model, in which growth producing interaction occurs, should guide future maltreatment research. Overall, change in relational growth and development can occur in the face of maltreatment through the establishment of mutuality and empathetic exchanges that may begin with the therapeutic alliance, which facilitates the journey from abuse related disconnection to relational reconnection.

\section{References}

American Humane Association. (2003). Child physical abuse [Fact sheet]. Retrieved from http://www.prandicenter.org/files/45432467.pdf

Azar, S. (2005). Physical abuse and neglect in girls. In D. J. Bell, S. L. Foster, \& E. J. Mash (Eds.), Handbook of behavioral and emotional problems in girls (pp. 312-356). New York, NY: Kluwer Academic/Plenum.

Benedini, K. M., Fagan, A. A , \& Gibson, C. L. (2016). The cycle of victimization: The relationship between childhood maltreatment and adolescent peer victimization. Child Abuse \& Neglect, 59, 111-121.

Birrell, P. J., \& Freyd, J. J. (2006). Betrayal trauma: relational models of harm and healing. Journal of Trauma Practice, 5, 49-63. 
Bishaw, A. (2011). Poverty: 2009 and 2010 American community survey briefs. Washington, DC: U.S. Census Bureau.

Bolger, K. E., \& Patterson, C. J. (2001). Developmental pathways from child maltreatment to peer rejection. Child Development, 72, 549-568.

Bundy-Fazioli, K., \& Delong Hamilton, T. A. (2013). A qualitative study exploring mothers' perceptions of child neglect. Child \& Youth Services, 34, 250-266.

Carr, A. (2019). Family therapy and systemic interventions for child-focused problems: The current evidence base. Journal of Family Therapy, 41, 153-213

Cashmore, J. (2011). The link between child maltreatment and adolescent offending: Systems neglect of adolescents. Family Matters, 89, 31-41.

Chen, W.-Y., Propp, J., \& deLara, E. (2011). Child neglect and its association with subsequent juvenile drug and alcohol offense. Child and Adolescent Social Work Journal, 28, 273-290.

Covington, S. (2007). The relational theory of women's psychological development: Implications for the criminal justice system. In R. Zaplin (Ed.), Female offenders: Critical perspectives and effective interventions (pp. 1-25). Sudbury, MA: Jones and Barlett.

Daniel, B. (2015). Why have we made neglect so complicated? Taking a fresh look at noticing and helping the neglected child. Child Abuse Review, 24, 82-94.

Evans, C. B. R., \& Burton, D. (2013). Outcomes of child maltreatment and trauma. Five types of child maltreatment and subsequent delinquency: Physical neglect as the most significant predictor. Journal of Child and Adolescent Trauma, 6, 231-245.

Guterman, N. B., \& Taylor, C. (2014). The prevention of physical child abuse and neglect. In P. Hess \& G. Mallon (Eds.), Child welfare for the twenty-first century: A handbook of practices, policies, and programs. (pp. 207-235). New York, NY: Columbia University Press.

Hunter, W., \& Knight, E. C. (1998, Summer). LONGSCAN research briefs. Washington, DC: National Center on Child Abuse and Neglect.

Jackson, Y., Cushing, C., Gabrielli, J., Fleming, K., O’Connor, B., \& Huffhines, L. (2016). Child maltreatment, trauma, and physical health outcomes: The role of abuse type and placement moves on health conditions and service use for youth in foster care. Journal of Pediatric Psychology, 41, 28-36.

Jonson-Reida, M., Chianga, C., Kohla, P., Drakea, B., Browna, D., Guoa, S., . . McBridea, T. (2019). Repeat reports among cases reported for child neglect: A scoping review. Child Abuse \& Neglect, 92, 43-65.

Jordan, J. V. (2001). A relational cultural model: Healing through mutual empathy. Bulletin of the Menninger Clinic, 65, 92-103.

Jordan, J. V. (2010). Relational cultural therapy. Washington, DC: American Psychological Association.

Kaehler, L. A., Babcock, R., DePrince, A. P., \& Freyd, J. J. (2013). Betrayal trauma. In J. D. Ford \& C.A. Courtois (Eds.), Treating complex traumatic stress disorders in children and adolescents: scientific foundations and therapeutic models (pp. 62-78). New York, NY: Guilford.

Kim, J., \& Cicchetti, D. (2010). Longitudinal pathways linking child maltreatment, emotion regulation, peer relations, and psychopathology. Journal of Child Psychology and Psychiatry 51, 706-716. 
Knight, E. D., Smith, J. B., \& Martin, L. M. (2010). Measures for assessment of functioning and outcomes in longitudinal research on child abuse Volume 3: Early adolescence. Chapel Hill, NC: University of Carolina at Chapel Hill, LONGSCAN Coordinating Center.

Laursen, B., \& Collins, W. A. (2009). Parent-child relationships during adolescence. In R. M. Lerner \& L. Steinberg (Eds.), Handbook of adolescent psychology (3rd ed., pp. 3-42). Hoboken, NJ: John Wiley and Sons.

Manion, K. (2011). Focusing on the child: Redressing neglect in child protection. Social Work Now, 48. $25-32$.

McLeod, G. F. H., Fergusson, D. M., \& Harwood, L. J. (2014). Childhood physical punishment or maltreatment and partnership outcomes at age 30. American Journal of Orthopsychiatry, 84, 307-315.

Miller, J. B. (2008). Connections, disconnections, and violations. Feminism \& Psychology 18, 368.

Muller, R.T., Thornback, K., \& Bedi, R. (2012). Attachment as a mediator between childhood maltreatment and adult symptomatology. Journal of Family Violence, 27, 243-255.

Pecora, P. J., Sanders, D., Wilson, D., English, D., Puckett, A., \& Rudlang-Perman, K. (2014). Addressing common forms of child maltreatment: Evidence-informed interventions and gaps in current knowledge. Child and Family Social Work, 19, 321-332.

Perry, B. D. (2001). Bonding and attachment in maltreated children: Consequences of emotional neglect in childhood. Retrieved from www.ChildTrauma.org.

Ramirez, D. E. N. (2016). Parent-child relationships and its effect on adolescence. Scholars, 28, $1-19$.

Ryan, J. P., Williams, A. B., \& Courtney, M. E. (2013). Adolescent, neglect, juvenile delinquency and the risk of recidivism. Journal of Youth Adolescence, 42, 454-465.

Runyan, D., Dubowitz, H., English, D. J., Kotch, J. B., Litrownik, A., Thompson, R., \& The LONGSCAN Investigator Group. (2014). Longitudinal Studies of Child Abuse and Neglect (LONGSCAN) Assessments 0-18 [Dataset]. Retrieved from http://www.ndacan.cornell.edu

Sigad, L. I., Beker, G., Lev-Wiesel, R., \& Eisikovits, Z. (2015). Living on the edges: Between victims and survivors, the voices of abused adolescent girls. Journal of Family Violence, 30, 621-631.

Toth, S. L., Gravener-Davis, J. A., Guild, D. J., \& Cicchetti, D. (2013). Relational interventions for child maltreatment: Past, present, and future perspectives. Development and Psychopathology, 25, 1601-1617.

Tucker, J. S., Edelen, M. O., Ellickson, P. L., \& Klein, D. L. (2011). Running away from home: A longitudinal study of adolescent risk factors and young adult outcomes. Journal of Youth Adolescence, 46, 507-518.

Unger, J. M., \& De Luca, R. V. (2014). The relationship between childhood physical abuse and adult attachment styles. Journal of Family Violence, 29, 223-234.

U.S. Department of Health \& Human Services, Administration for Children and Families, Administration on Children, Youth and Families, Children's Bureau. (2012). Child Maltreatment 2011. Retrieved from http://www.acf.hhs.gov/programs/cb/research-datatechnology/statistics-research/child-maltreatment

U.S. Department of Health \& Human Services, Administration for Children and Families, Administration on Children, Youth and Families, Children's Bureau. (2018). Child maltreatment 2016. Retrieved from https://www.acf.hhs.gov/cb/research-datatechnology/statistics-research/child-maltreatment 
Vandermindena, J., Hambyb, S., David-Ferdonc, C., Kacha-Ochanad, A., Merrickc, M., Simonc, T.R. . .. Turnere, H. (2019). Rates of neglect in a national sample: Child and family characteristics and psychological impact. Child Abuse \& Neglect, 88, 256-265.

Warmuth, K. A., \& Cummings, M. E. (2015). Examining developmental fit of the Adult Attachment Interview in adolescence. Developmental Review, 36, 200-218.

Withers, M. C., McWey, L. M., \& Lucier-Greer, M. (2016). Parent-adolescent relationship factors and adolescent outcomes among high-risk families. Family Relations, 65, 661-672.

World Health Organization. (2016, September 30). Child maltreatment fact sheet. Retrieved from https://www.who.int/en/news-room/fact-sheets/detail/child-maltreatment

Yoon, D., Yoon, S., Park, J., \& Yoon, M. (2018). A pernicious cycle: Finding the pathways from child maltreatment to adolescent peer victimization. Child Abuse \& Neglect, 81, 139-148.

The Journal of Social, Behavioral, and Health Sciences is an open-access, peer-reviewed, online interdisciplinary journal focusing on research findings that address contemporary national and international issues. Its objectives are to (a) encourage dialogue between scholars and practitioners in the social, behavioral, and health sciences that fosters the integration of research with practice; (b) promote innovative models of interdisciplinary collaboration among the social, behavioral, and health sciences that address complex social problems; and (c) inform the relationship between practice and research in the social, behavioral, and health sciences.

Walden University Publishing: http://www.publishing.waldenu.edu 